\title{
Every Writer has a Story to Tell, everyone is a Writer: Three Case Histories Utilizing Creative Writing in Therapy
}

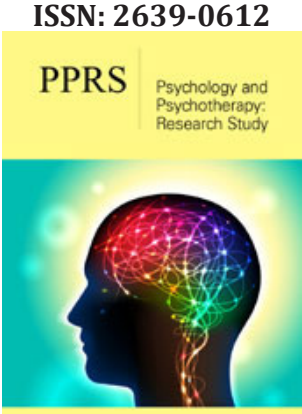

*Corresponding author: Riccardo Natale Caniato, Consultant Psychiatrist, Fellow of the Royal Australian and New Zealand College of Psychiatrists, Fulham Consulting, Australia

Submission: 澅 September 02, 2019

Published: 㭰 October 14, 2019

Volume 2 - Issue 5

How to cite this article: Riccardo Natale Caniato, Amy Sellers. Every Writer has a Story to Tell, everyone is a Writer: Three Case Histories Utilizing Creative Writing in Therapy. Psychol Psychother Res Stud. 2(5).PPRS.000546.2019.

DOI: 10.31031/PPRS.2019.02.000546

Copyright@ Riccardo Natale Caniato This article is distributed under the terms of the Creative Commons Attribution 4.0 International License, which permits unrestricted use and redistribution provided that the original author and source are credited.

\author{
Riccardo Natale Caniato ${ }^{1 *}$ and Amy Sellers ${ }^{2}$ \\ ${ }^{1}$ Consultant Psychiatrist, Australia \\ ${ }^{2}$ Clinical Psychologist, Australia
}

\begin{abstract}
Therapy is usually administered in a spoken format. Verbal communication forms the major basis of the psychiatric process. Creative writing however can be a valuable adjuvant to the psychotherapeutic process, allowing another avenue for analysis, re-framing and healing. Encouraging a patient to express and explore issues through their writing can in some patients prove extremely therapeutic. We present three case histories to highlight the potential role of writing in treatment and therapy.
\end{abstract}

\section{Introduction}

\section{Creative writing as therapy}

"Every secret of a writer's soul, every experience of his life, every quality of his mind, is written large in his works." -Virginia Woolf

Every person has at least one book in them waiting to be written. So, it is true of every patient. Every patient has a story or narrative. Often our role is to explore this narrative in therapy, helping the patient retell their story in a new, more empowering way. I (first author) encourage my patients to write, and to show me their manuscripts. When I ask my patients about their writing, a surprising number admit to me they have written or have started writing a book or novel. Usually this a stop-start affair, with most having lost motivation halfway through the book. I encourage them to continue writing. Often, I offer to read their drafts. Surprisingly I find that most of my patients are very reluctant to let me read their work. These people have at times confided some of their darkest and most personal moments to me, but their writing, this is off limits, even to their psychiatrist. In writing we leave ourselves most vulnerable. 'Every secret of a writer's soul' is revealed in his works. Writing, even if fictional, is a form of self-disclosure. Writing is a type of self-directed narrative therapy and an opportunity to acknowledge, reveal and re-write the hurts of the past. Trauma, minor or severe, disrupts one's personal narrative through violation of core beliefs about the self, others and the world [1]. Incomplete narratives promote distress [2]. Writing as a therapeutic technique has been hypothesised to improve stress through the mechanisms of disinhibition, exposure [3], emotional expression, cognitive processing [4], cognitive restructuring and cognitive reappraisal [5].

While different narrative techniques produce different results [6] I have observed that the process of editing a manuscript provides an additional element to the therapeutic process. The intensely personal nature of a writer's work, even when presented as 'fiction', demands that a person's inner-most thoughts and feelings must be transcribed into a work which is fit for public consumption [1]. Producing a manuscript worthy of publishing transforms confusing, shameful or distressing personal histories into cohesive and masterful stories in a reflection of the writer's personal transformation [7]. Skills in writing narratives with cohesive plots and well-developed sense of meaning are linked to improved coping skills for stress and trauma [4]. I have found that patients, with time, will entrust to me their manuscript, not because of my position as their therapist, but perhaps more as a fellow writer. Nearly always, examination of their writing bears fruit. 
"Everyone has a story to tell. Everyone is a writer; some are written in the books and some are confined to hearts." - Savi Sharma

\section{Case Reports}

\section{Case A: The science fiction writer}

Mr A was seeing me for anxiety. He was a public servant of many years, but anxiety and lack of confidence had caused his career to stall. He was writing a science fiction novel. It was an intergalactic space opera, in the tradition of Robert Heinklen or Isacc Asimov. He was struggling with one of the characters, Tiberious. He had written a chapter where Tiberious teaches his son a lesson, by promising to catch him, but then deliberately letting him fall. "This is to teach you to never trust anyone, not even your father". The story then moved on to the next chapter. I asked Mr A about this. I wanted more detail about Tiberious. I asked him, "Is he a good or bad person?" Mr A shook his head. "I don't really know". I asked him if Tiberious was based on his own father. "Of course." That was simple. As therapy progressed, we concluded that his inability to reconcile Tiberious as a character reflected his inability to reconcile his own father's behaviour. He was ultimately able to finish the chapter and his book. His anxiety issues improved and after twelve months of therapy we decided to end therapy. He has not returned to treatment and when we last spoke his career was going well. All writing is at some level autobiographical. It is a perfect place to explore unresolved trauma [7]. Exploring traumatic memories is not only distressing, it can open old wounds so that functioning is significantly impaired [1]. Examining one's past through the eyes of a character may provide the necessary safety to approach past hurts and make sense of harmful experiences.

\section{Case B: The police officer}

Ms B had a ten-year history of debilitating PTSD from police work. I was one of a long list of previous therapists. I had been seeing her for monthly supportive psychotherapy for over three years, when she first told me of her desires to write a book of her own experiences. After a few months of encouragement, she joined a writers group. A few months later she shoved me her first manuscript. She has written about a specifically traumatic case she had been involved in. I read the manuscript. It was a moving story of a victim of domestic violence, written in the third person. There was no mention of Ms B anywhere in the manuscript. I asked her why she wasn't in the manuscript and she explained that it was for reasons of confidentiality. As treatment progressed, she began to reveal how powerless she had felt while she was working this case. She had been unable to help this woman, who kept returning to the abusive relationship. Ultimately the woman was murdered, burdening Ms B with a sense of guilt and powerlessness.

Ms B continued to rewrite her manuscript. Eventually she presented me with a manuscript in which she featured. It was still written in the third person, but she had been added in the story. She was able to recall more and more details of her own involvement in the crime, which she presented in the story. Finally, she presented me with a large binder. "I think this is it," she told me. It was the history of this whole incident, written in the first person. She told me that she could now feel proud for her actions. She had done her best to help the girl and she knew that now. Cognitive re-framing is a core feature of many successful trauma therapy approaches [8]. For Ms B this meant a new definition of her role in the case and an appreciation of her actions. When trauma breeds powerlessness and powerlessness breeds silence, then the path back to personal mastery and pride is paved with speaking out, phrasing, writing, re-phrasing and re-writing [1].

\section{Case C: The children's writer}

At times it is re-writing one's past actions that gives a sense of meaning to an experience [7]. For my third patient, editing the manuscript of his own thoughts and feelings was what was most important. Mr C was a fifty-five-year-old editor with a history of schizoaffective disorder. I had treated him for over fifteen years. He had maintained employment during his adult life as a magazine editor but had chronic residual hallucinations. The hallucinations took the form of the devil talking to him and telling him things such as he will burn in hell. Over the years he had come to accept that they were not real, though the content of the hallucinations remained distressing. Mr C's interest outside work was writing and he had self-published a children's novel. His second book however had been stalling. This book was a fictional book about a man's experience with mental illness. He was struggling to begin the third chapter. It was the period where his protagonist was hospitalised in a mental institution. The novel of course was semiautobiographical, drawing on Mr C's own experience with mental illness. His first hospitalisation with psychosis had been in his late twenties. It was still a very painful memory.

He had harboured a great deal of guilt and sadness, and he still blamed himself for his illness. We had explored these issues before. This time I encouraged him to explore these issues through his book's protagonist, Jason. It took a further six months, but he was able to complete the manuscript. Perhaps it was a process of engaging with his protagonist or finding forgiveness for himself [9] that brought Mr C closure. "I guess Jason was not such a bad person after all. Just a victim of circumstance," he told me in the subsequent sessions. The hallucinations are still present, but they were not so angry or negative.

"Sometimes Lucifer even says nice things. Maybe he is not such a bad guy after all" [10].

\section{Conclusion}

All patients have a story or narrative to tell. Mental distress in many cases is perpetuated by an unfinished story [2]. Perhaps it is unresolved, incomplete or unreadable. Whatever the reason, the solution to any bad manuscript is to revise and edit. The same can be said of the inner story: multiple revisions may be required to make sense of a life and foster self-understanding. With enough perseverance all stories can be salvaged and made publishable. I encourage many of my patients to write. I consider it an important adjuvant to therapy and medications. The process of writing can be reparative and uplifting. Ultimately, I hope that one of my patients will write a bestselling book, but that is never the point of writing. 
The process of putting pen to paper is only ever a personal journey. Everyone has a life that is worth living to the full, and a story worth writing.

\section{References}

1. Van der kolk BA (2014) The body keeps the score: brain, mind and body in the healing of trauma. Viking Penguin, USA.

2. Wigren J (1994) Narrative completion in the treatment of trauma. Psychotherapy: Theory, Research, Practice, Training 31(3): 415-423.

3. Bootzin RR (1997) Examining the theory and clinical utility of writing about emotional experiences. Psychological Science 8(3): 167-169.

4. Peterkin AD, Prettyman AA (2009) Finding a voice: revisiting the history of therapeutic writing. Med Humanit 35(2): 80-88.

5. Lu Q Stanton AL (2010) How benefits of expressive writing vary as a function of writing instructions, ethnicity and ambivalence over emotional expression. Psychol Health 25(6): 669-684.
6. Emmerik AAP, Reijntjes A, Kamphius JH (2013) Writing therapy for posttraumatic stress: a meta-analysis. Psychother Psychosom 82(2): 8288.

7. Gonçlaves OF (1994) Cognitive narrative psychotherapy: the hermeneutic construction of alternative meanings. Journal of Cognitive Psychotherapy 8(2): 105-125.

8. Lenz S, Brujin B, Sherman NS, Bailey L (2014) Effectiveness of cognitive processing therapy for treating posttraumatic stress disorder. Journal of Mental Health Counseling 36(4): 360-376.

9. Orcutt HK, Pickett SM, Pope EB (2005) Experiential avoidance and forgiveness as mediators in the relation between traumatic interpersonal events and posttraumatic stress disorder symptoms. Journal of Social and Clinical Psychology 24(7): 1003-1029.

10. Sharma S (2015) Everyone has a story. Westland, India. 